\title{
Multi-wavelength Q-switched erbium-doped fibre laser using saturable absorber based on carbon nanotube film
}

\author{
${ }^{1}$ Anyi C. L., ${ }^{1}$ Ali N. M., ${ }^{2}$ Rahman A. A., ${ }^{1}$ Harun S. W. and ${ }^{1}$ Arof H. \\ ${ }^{1}$ Department of Electrical Engineering, Faculty of Engineering, University of \\ Malaya, 50603, Kuala Lumpur, Malaysia, e-mail: ahamzah@um.edu.my \\ ${ }^{2}$ Faculty of Computer \& Mathematical Sciences, University of Technology MARA \\ Kelantan, Bukit Ilmu, 18500 Machang, Kelantan, Malaysia
}

Received: 12.08 .2013

\begin{abstract}
A stable passively Q-switched multi-wavelength erbium-doped fibre laser operating near $1533.5 \mathrm{~nm}$ is demonstrated using a saturable absorber based on single-walled carbon nanotube film, which is prepared using polyvinyl alcohol as a host polymer. The laser achieves a multi-wavelength oscillation regime as a result of nonlinear polarization rotation effect, which overcomes unstable mode competition in the ring cavity. It generates a stable multi-wavelength comb of seven lines, with the wavelength spacing of $0.10 \mathrm{~nm}$ at the pump power $64 \mathrm{~mW}$. At the same pump power, the laser produces a stable pulse train with the repetition rate $13.1 \mathrm{kHz}$, the pulse width $7.2 \mu \mathrm{s}$ and the pulse energy $21 \mathrm{~nJ}$. A high performance of our Qswitched laser is achieved by optimizing the saturable absorber and the laser cavity.
\end{abstract}

Keywords: carbon nanotubes/polyvinyl alcohol film, Q-switching, passive Q-switcher, multi-wavelength erbium-doped fibre laser

PACS: 42.60.Da, 42.55.Wd, 42.65.Re, 42.60.Gd

UDC: $535.37+681.7 .068$

\section{Introduction}

It is known that lasers operating in continuous wave or quasi-continuous wave regimes have a limited optical output power, depending on the maximum pump power. By concentrating the available energy in a single short optical pulse, or in a periodic sequence of pulses, higher peak powers are achievable. Q-switching is a technique that enables generation of short optical pulses by sudden switching of Q-factor of a cavity (in fact, a cavity loss). When compared to continuous wave fibre lasers, high peak-power Q-switched fibre lasers find some additional applications, such as range finding, remote sensing, industrial processing, and medical applications [1-3]. Active Qswitching is typically implemented via inserting acoustooptic or electrooptic modulators into the cavity [4]. On the other hand, passive Q-switching by means of saturable absorbers (SAs) represents a convenient technique that simplifies design of the cavity and requires no external Qswitching electronics. So far, transition-metal doped crystals [5] and semiconductor SA-mirrors [6] have been extensively employed as SAs in the Q-switched fibre laser systems. However, these SAs are complex and expensive. Furthermore, they are not compatible with many optical fibres, thus narrowing a range of possible applications.

Recently, a simple and cost-effective alternative based upon single-walled carbon nanotubes (SWCNT) has been tested and shown to be advantageous [7]. The benefits of SWCNT absorbers include ultrafast recovery time, large saturable absorption, ease of fabrication, and low cost. One of the ways for implementing SWCNT-based SAs is to embed an SWCNT into a polymer matrix to form a composite. This method seems to be promising since it allows for excellent 
homogeneous dispersion of the SWCNT and, moreover, a resulting composite can be used to fabricate thin films. Up to date, many works have been reported on the integration of SWCNT/polyvinyl alcohol (PVA) SAs into fibre laser systems for ultra-short pulse generation (see, e.g., [8]). However, most of the works involving the SWCNT-based SAs have been directed at building mode-locked fibre lasers [9, 10], while Q-switched fibre lasers have been addressed seldom enough [11]. Besides, a few works reported on the Q-switched lasers have been focused mainly on single-wavelength operation $[2,11]$.

In this paper, a Q-switched multi-wavelength erbium-doped fibre laser (EDFL) is demonstrated using a simple and low-cost SWCNT-based SA, which is prepared using the PVA as a host polymer. The multi-wavelength operation is achieved based on a nonlinear polarization rotation effect in the ring cavity. The SA is integrated in the EDFL ring cavity by sandwiching the SWCNT/PVA thin film between two fibre connectors. A stable pulse train with the repetition rate $13.1 \mathrm{kHz}$, the pulse width $7.2 \mu \mathrm{s}$, and the pulse energy $21 \mathrm{~nJ}$ is reached, when the EDFL ring cavity is pumped by a $980 \mathrm{~nm}$ laser diode at the pump power of $64 \mathrm{~mW}$.

\section{Experimental procedures}

A key component of our Q-switching technique is fabrication of an SA that incorporates dispersed SWCNT. To match the EDFL operating at $1550 \mathrm{~nm}$, choosing of the SWCNT with suitable average diameter and distributed diameter range is a crucial step. In this work, we used the SWCNT with the purity of $99 \%$, the diameter distributed within 1-2 nm, and the length of 3$30 \mu \mathrm{m}$. The PVA representing a water-soluble synthetic polymer with the monomer formula $\mathrm{C}_{2} \mathrm{H}_{4} \mathrm{O}$ served as a host material. It had excellent film-forming, emulsifying and adhesive properties. It also manifested high tensile strength, flexibility, oxygen and aroma barrier properties, although these were dependent on the humidity. Since it was difficult to disperse the SWCNT in water, a sodium dodecyl sulphate solvent (the average molecular weight of $288.38 \mathrm{~g} / \mathrm{mol}$ ) was used to prepare a homogeneous solution of the SWCNT. The sodium dodecyl sulphate enabled dispersing the SWCNT, with good dispersing stability in the water.

Fabrication of the SA comprised three major stages. First, we mixed the SWCNT and the dispersant in the water to form a hybrid solution. We stirred the latter for an hour using an ultrasonic cleaner to disperse the SWCNT uniformly, with a suitable ratio of contents of all inclusions. The solution was centrifuged at $1000 \mathrm{rpm}$ to remove large particles of undispersed SWCNT and obtain a dispersed suspension stable for weeks. Second, we prepared a PVA solution by dissolving $1 \mathrm{~g}$ of the PVA in $400 \mathrm{ml}$ of distilled water. Then we mixed the PVA solution with the hybrid SWCNT solution, thus forming a precursor. Then the mixture was stirred for about one hour with an ultrasonic cleaner. This step helped us get the precursor with high enough viscosity so that it could easily be used when forming the SWCNT/PVA film. Finally, suitable amounts of the precursor were spread thinly upon a glass substrate and let dry at the room temperature to form the SA film.

The experimental setup of our Q-switched multi-wavelength EDFL is shown in Fig. 1. It consists of a $1 \mathrm{~m}$ long erbium-doped fibre (EDF), a 980/1550 nm wavelength division multiplexer, an isolator, an SA based on the SWCNT/PVA film, and a 95/5 output coupler in a ring configuration. The SA was fabricated by cutting a small part of a film $\left(2 \times 2 \mathrm{~mm}^{2}\right)$ prepared earlier and sandwiching it in between two FC/PC fibre connectors, after depositing an index-matching gel onto the fibre ends. The insertion losses of the SA were measured to be about $1.5 \mathrm{~dB}$ at $1550 \mathrm{~nm}$. The EDF used by us had the core and cladding diameters respectively $4 \mu \mathrm{m}$ and $125 \mu \mathrm{m}$, the 
numerical aperture 0.16 and the erbium ion absorption $23 \mathrm{~dB} / \mathrm{m}$ at $980 \mathrm{~nm}$. It was pumped by a $980 \mathrm{~nm}$ laser diode via the wavelength division multiplexer. An isolator was incorporated in the laser cavity to ensure unidirectional propagation. The output of the laser was tapped out of the cavity through the $95 / 5$ coupler so as to keep $95 \%$ of light to oscillate in the ring cavity. We analyzed the spectrum of the Q-switched EDFL with an optical spectrum analyzer (the spectral resolution $0.02 \mathrm{~nm}$ ). An oscilloscope was used to observe the output pulse train via a $460 \mathrm{kHz}$ bandwidth photodetector (Thor Lab, PDA50B-EC). The total cavity length of the ring resonator was equal to $\sim 3 \mathrm{~m}$.

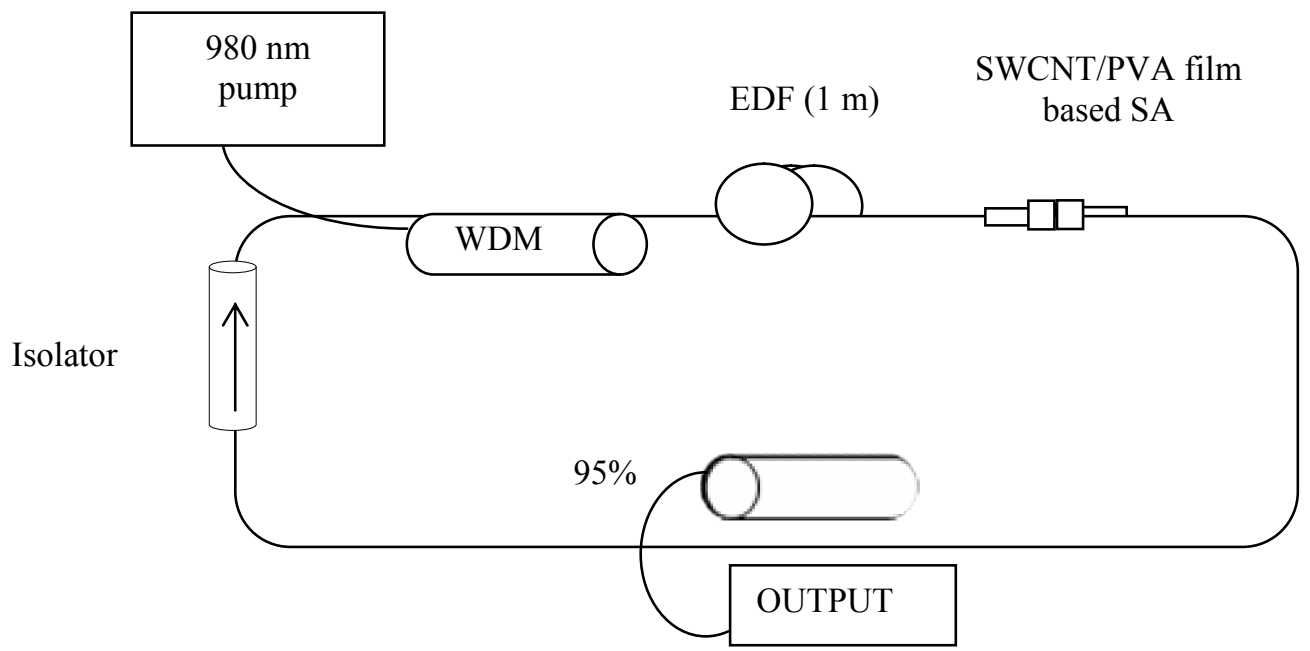

Fig. 1. Schematic configuration of our Q-switched multi-wavelength EDFL. WDM is a wavelength division multiplexer.

\section{Results and discussion}

Fig. 2 shows the output spectra of our EDFL at three different pump powers $(53,64$ and $76 \mathrm{~mW})$. The multi-wavelength oscillation is achieved in all of the spectra due to a nonlinear polarization rotation effect. The latter overcomes unstable mode competition in the ring cavity. The laser generates a stable multi-wavelength output with the wavelength spacing of $0.10 \mathrm{~nm}$ at the pump power of $64 \mathrm{~mW}$. It generates seven lines with an optical signal-to-noise ratio exceeding $6 \mathrm{~dB}$. The multi-wavelength generation is due to combined utilizing of the EDF and the SWCNT/PVA SA, both of which reveal very high nonlinearities. It is known that our EDF (the core diameter of $4 \mu \mathrm{m})$ reveals high nonlinearity, whereas the SWCNT is a high-birefringence material. The nonlinear polarization rotation occurs in the ring cavity due to the presence of linear birefringence, which induces a phase shift and changes the polarization state of light from linear to elliptical. The isolator is a key element, which works together with the EDF and the SA to generate intensitydependent transmission. The EDF increases the nonlinear effect and forms an in-line periodic birefringence fibre filter with the aid of the optical isolator in the ring cavity.

The laser suggested here operates with a negative feedback since the cavity transmittance decreases with increasing light power. In other words, higher-intensity input light experiences higher losses, and this serves as intensity equalizer. The intensity-dependent loss is used for suppressing competition of laser modes resulting from homogeneous gain broadening in the EDF, thus stabilizing the room-temperature multi-wavelength oscillations. The multi-wavelength generation regime could be further stabilized by four-wave mixing effect in the ring cavity. Notice 
that with no SWCNT/PVA SA included, the laser operates at $1534 \mathrm{~nm}$ in the random mode as shown in Fig. 3.
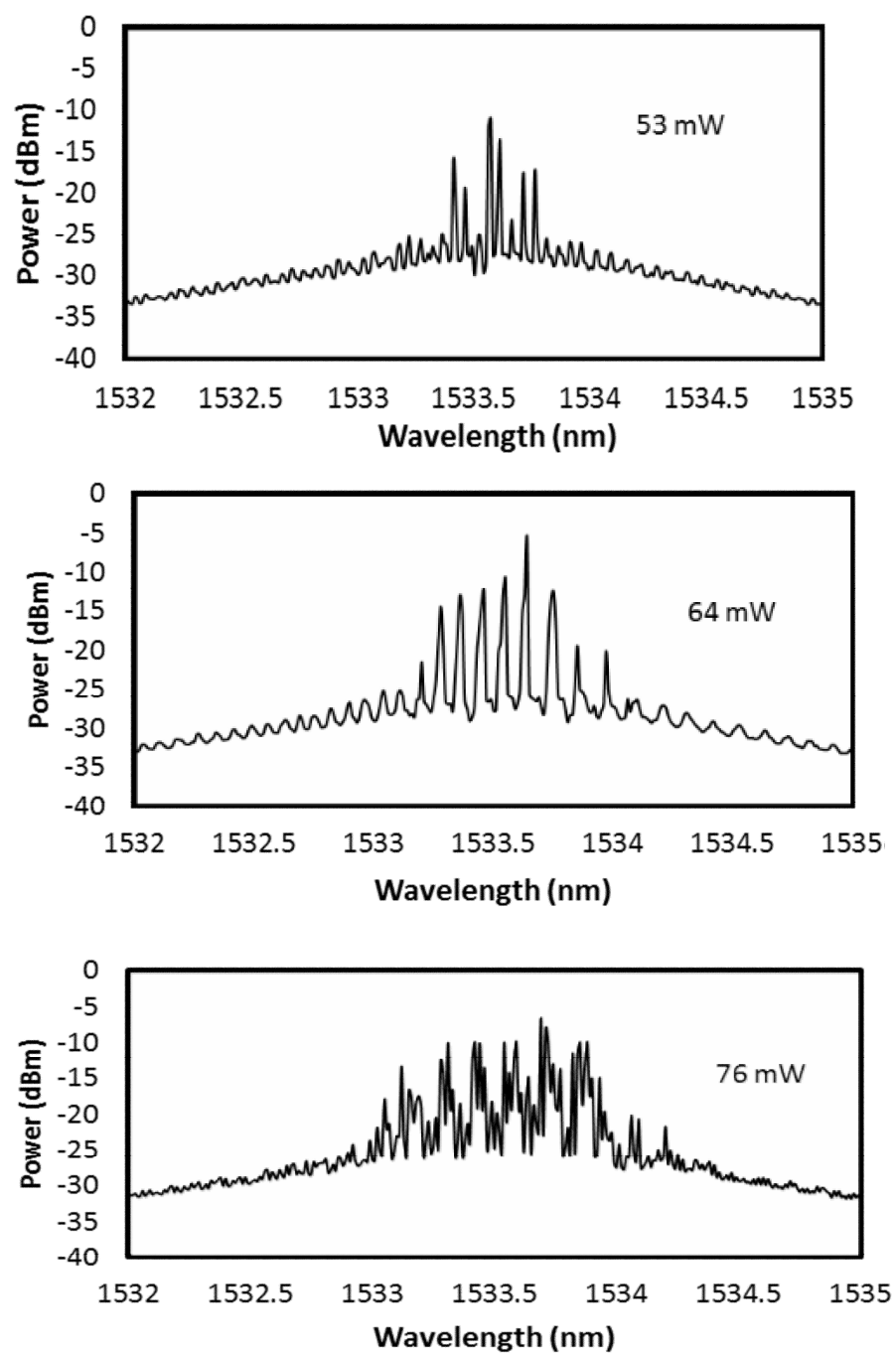

Fig. 2. Output spectra of our EDFL observed at three different pump powers: 53 , 64 , and $76 \mathrm{~mW}$.

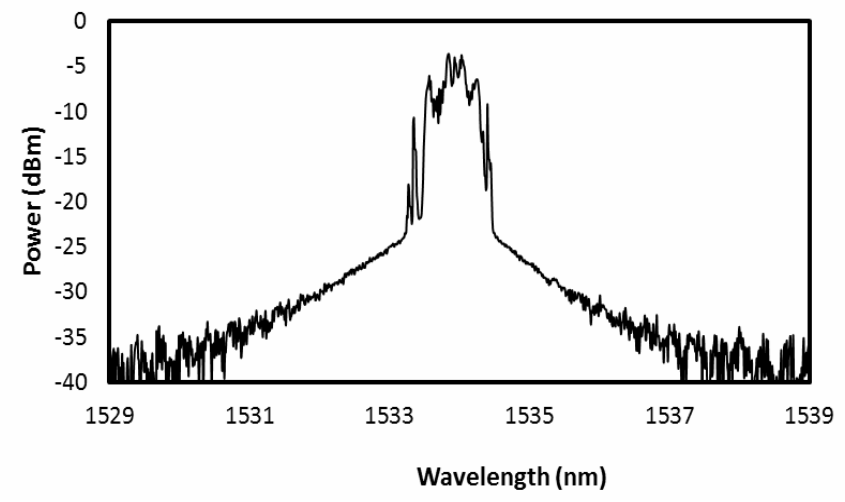

Fig. 3. Output spectrum of our EDFL configured with no SA, as observed at the pump power $64 \mathrm{~mW}$. 
Pump power $53 \mathrm{~mW}$ and repetition rate $8.8 \mathrm{kHz}$
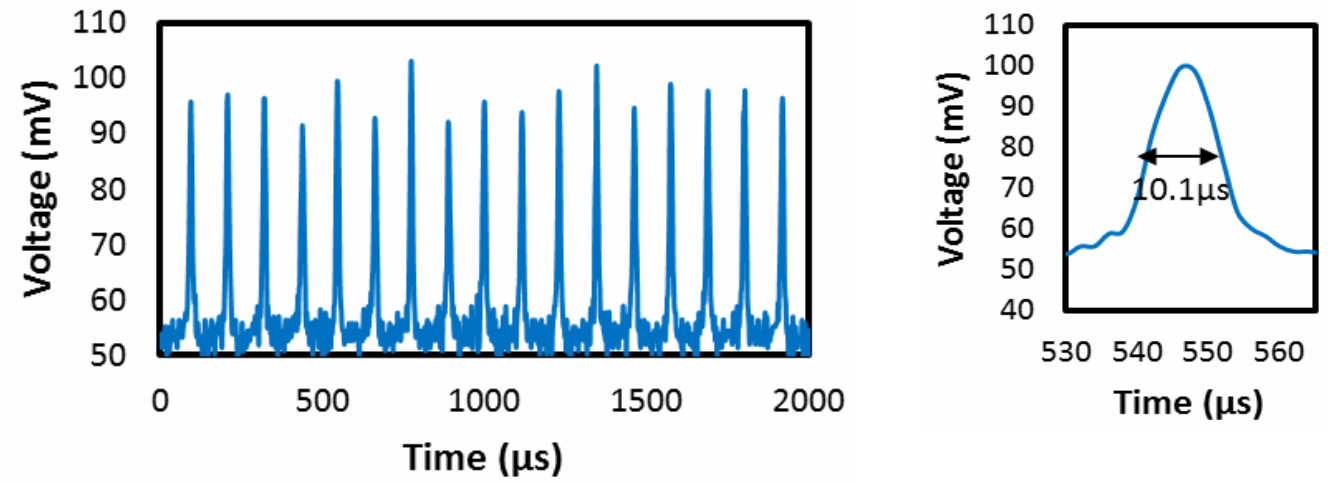

Pump power $64 \mathrm{~mW}$ and repetition rate $13.1 \mathrm{kHz}$
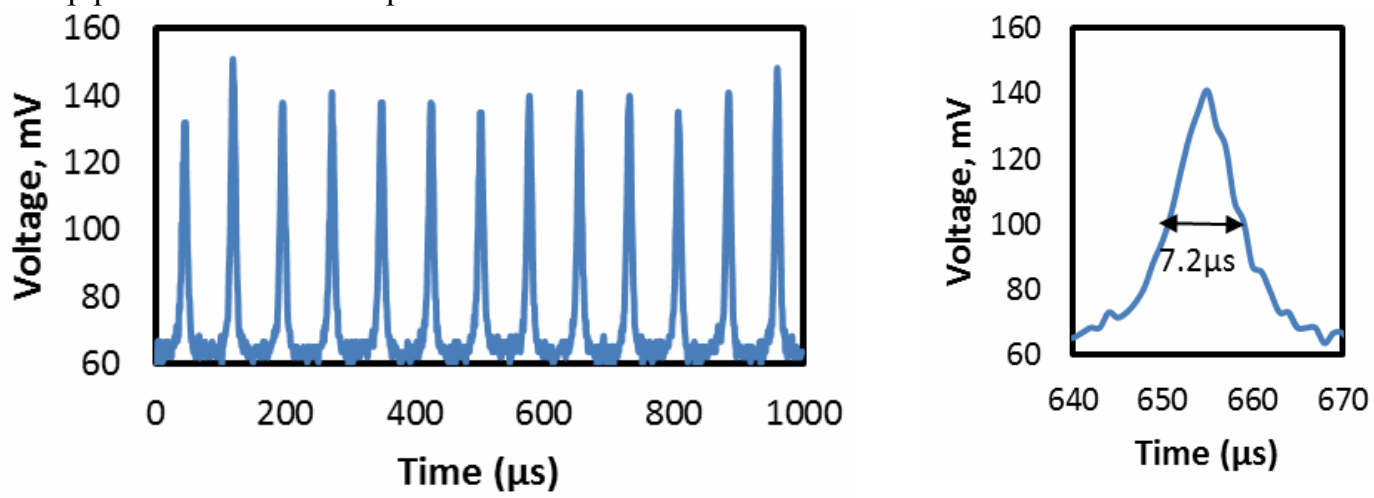

Pump power $76 \mathrm{~mW}$ and repetition rate $20.4 \mathrm{kHz}$
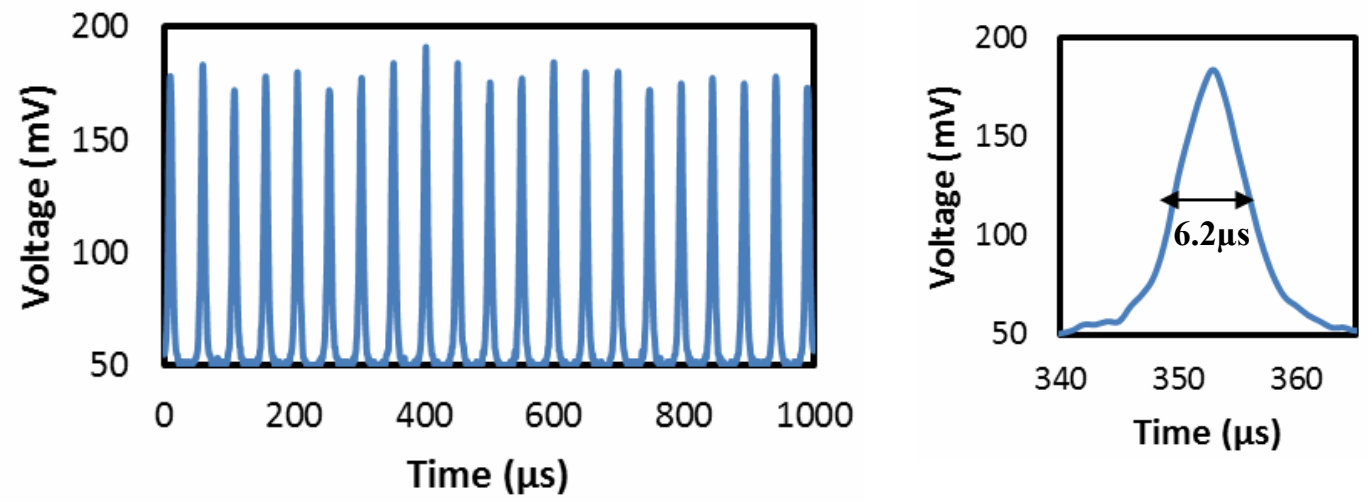

Fig. 4. Pulse trains (left panels) and single-pulse envelops (right panels) typical for our Q-switched EDFL at different pump powers and repetition rates.

Stable and self-starting Q-switching is obtained whenever the pump power exceeds a $47 \mathrm{~mW}$ threshold. Fig. 4 shows the oscilloscope traces of the Q-switched pulse trains and the pulse envelops at three different pump powers $(53,64$ and $76 \mathrm{~mW})$. There is no distinct amplitude modulation in each of the Q-switched envelop spectra, which indicates that the influence of selfmode locking on the Q-switching is weak. At the $64 \mathrm{~mW}$ pump power, a stable passive Qswitching operation regime is achieved, with the average output power of $0.27 \mathrm{~mW}$, the repetition rate of $13.1 \mathrm{kHz}$ and the pulse width of $7.2 \mu \mathrm{s}$. For the pump power mentioned above, the pulse energy is calculated to be approximately $21 \mathrm{~nJ}$. The pulse energy could be improved by reducing the insertion loss of the graphene SA and optimizing the laser cavity. 


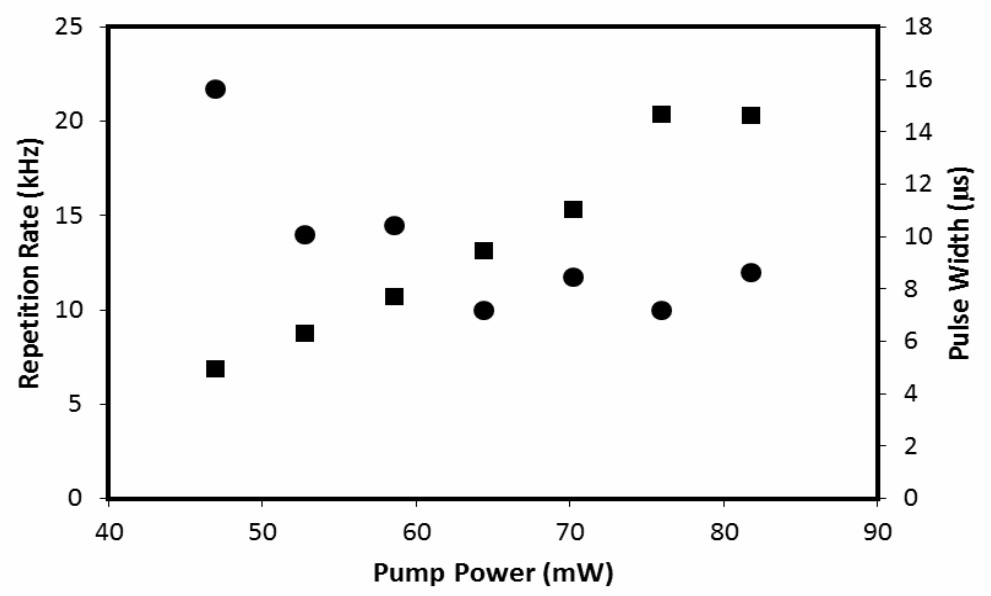

Fig. 5. Repetition rate and pulse width of the laser as functions of the $980 \mathrm{~nm}$ pump power.

Fig. 5 shows the repetition rate and the pulse width versus the pump power. The repetition rate of the Q-switched EDFL increases monotonically with increasing pump power level and depends almost linearly on the latter quantity. When the pump power increases from 47 up to $82 \mathrm{~mW}$, the pulse-train repetition rate is increased from 6.9 to $20.3 \mathrm{kHz}$. On the other hand, the pulse width becomes smaller as the pump power increases from 47 to $64 \mathrm{~mW}$, before fluctuating inside the region 7.2-8.6 $\mu$ s as the pump power is further increased. The shortest pulse width ( $7.2 \mu \mathrm{s}$ ) is typical for the pump power of $64 \mathrm{~mW}$. The pulse width is expected to decrease further when the total cavity length of the fibre laser is shortened.

\section{Conclusion}

We have demonstrated a stable passively Q-switched EDFL using an SA based on an SWCNT/PVA thin film. The film has been sandwiched between two ferrules and the SA has been incorporated in the EDFL ring cavity to yield in a Q-switched fibre laser operating in the vicinity of $1533.5 \mathrm{~nm}$. The laser has a multi-wavelength output due to the nonlinear polarization rotation effect in both the EDF and the SA, which suppresses mode competition in the ring cavity. At the pump power $64 \mathrm{~mW}$, the Q-switched laser produces at least seven lines with the spacing $0.10 \mathrm{~nm}$. The laser reveals the repetition rate of $13.1 \mathrm{kHz}$, the pulse width of $7.2 \mu \mathrm{s}$, and the pulse energy of $21 \mathrm{~nJ}$ at the pump power mentioned above. Besides of a good Q-switching performance, the SA is cheap and easy to fabricate. This makes the SA suggested by us a suitable component for multiwavelength Q-switched lasers emitting near $1.5 \mu \mathrm{m}$.

\section{Acknowledgement}

This work was supported by funding from the University of Malaya Research Grant Scheme (Grant No.: RG159-12AET).

\section{References}

1. Bao-Quan Y, Xiao Y, Xiao-Lei L, Xiao-Ming D, You-Lun J and Yue-Zhu W, 2013. A

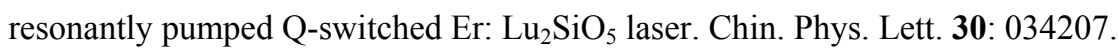

2. Harun S W, Ismail M, Ahmad F, Ismail M, Nor R, Zulkepely N and Ahmad H, 2012. A Qswitched erbium-doped fiber laser with a carbon nanotube based saturable absorber. Chin. Phys. Lett. 29: 114202. 
3. Ismail M A, Ahmad F, Harun S, Arof H and Ahmad H, 2013. A Q-switched erbium-doped fiber laser with a graphene saturable absorber. Laser Phys. Lett. 10: 025102.

4. Zhang G, Zhao S, Li Y, Li G, Li D, Yang K, Cheng K and Yu Z, 2011. Performance of doubly Q-switched and mode-locked $\mathrm{Nd}$ : $\mathrm{LuVO}_{4}$ laser with acousto-optic modulator and GaAs saturable absorber. Opt. Eng. 50: 074202.

5. Lei P, Utkin I and Fedosejevs R, 2007. Passively Q-switched ytterbium-doped double-clad fiber laser with a $\mathrm{Cr}^{4+}$ :YAG saturable absorber. IEEE Photon. Technol. Lett. 19: 19791981.

6. Huang J Y, Huang W C, Zhuang W Z, Su K W, Chen Y F and Huang K F, 2009. Highpulse-energy, passively Q-switched $\mathrm{Yb}$-doped fiber laser with AlGaInAs quantum wells as a saturable absorber. Opt. Lett. 34: 2360-2362.

7. Song Y-W, 2012. Q-switched fiber lasers with carbon nanotubes hosted in ceramics. Appl. Opt. 51: 290-294.

8. Castellani C E S, Kelleher E J R, Popa D, Hasan T, Sun Z, Ferrari A C, Popov S V and Taylor J R, 2013. CW-pumped short pulsed $1.12 \mu \mathrm{m}$ Raman laser using carbon nanotubes. Laser Phys. Lett. 10: 015101.

9. Cheng K-N, Lin Y-H and Lin G-R, 2013. Single-and double-walled carbon nanotube based saturable absorbers for passive mode-locking of an erbium-doped fiber laser. Laser Phys. 23: 045105.

10. Ismail M A, Harun S W, Zulkepely N R, Nor R M, Ahmad F and Ahmad H, 2012. Nanosecond soliton pulse generation by mode-locked erbium-doped fiber laser using singlewalled carbon-nanotube-based saturable absorber. App. Opt. 51: 8621-8624.

11. Zhou D-P, Wei L, Dong B and Liu W-K, 2010. Tunable passively Q-switched erbium-doped fiber laser with carbon nanotubes as a saturable absorber. IEEE Photon. Technol. Lett. 22: $9-11$.

Anyi C. L., Ali N. M., Rahman A. A., Harun S. W. and Arof H. 2013. Multi-wavelength Qswitched erbium-doped fibre laser using saturable absorber based on carbon nanotube film. Ukr.J.Phys.Opt. 14: $212-218$.

Анотація. Продемонстровано функціонування стабільного волоконного лазера на легованому ербії з пасивною модуляцією добротності, щзо випромінює на довжині хвилі 1533,5 нм. Лазер використовує плівковий поглинач, виготовлений на основі полівінілового спирту як гостьового полімеру і одностінних вуглецевих нанотрубок. Запропонований лазер забезпечує багатохвильові осиилящії внаслідок нелінійного повороту площиини поляризації, що приводить до подолання нестабільного режиму конкуренції мод в кільцевому резонаторі. За потужності нагнітання $64 \mathrm{mBm}$ лазер генерує стабільний багатохвильовий гребінь довжин хвиль, який складається з семи ліній, із щілинами між лініями 0,10 нм. 3 а такої ж потужності нагнітання лазер генерує стабільну послідовність імпульсів 3 частотою повторення 13,1 кГц, тривалістю імпульсів 7,2 мкс і енергією імпульсу 21 нДж. Кращі характеристики лазера можна досягнути шляхом оптимізачії поглинача в режимі насичення і лазерного резонатора. 